\title{
Combined Hepatic and Portal Vein Thrombosis due to Uncommon Hereditary Factors for Thrombophilia in Young Adult
}

\section{Afaf Hemeda*}

Department of Internal and Vascular Medicine, Kasr Al Eini Faculty of Medicine, Cairo University, Egypt

\begin{abstract}
Thrombophilia is an important medical problem that carries a great morbidity and mortality especially in young patients and great laboratory workup is usually needed to detect the underlying etiology. Several factors have been claimed to be responsible for thrombosis, some of them are common and others are not, the acquired causes represent the majority while hereditary causes are the minority. The case is an example for acute thrombosis in hepatic veins and chronic thrombosis in portal vein in a young adult that was addict for tramadol for last three years with excellent response to anticoagulation as regards hepatic vein thrombosis.
\end{abstract}

Keywords: Hereditary thrombophilic; Heterozygous; Homozygous; Portal cavernoma

\section{Case Report}

Thirty two years old, hair dresser single lady presenting with severe right hypochondrial pain and abdominal distension. She was addict for tramadol for past three years with no other special habits of medical importance.

The condition started with gradual onset and progressive course of right upper quadrant abdominal pain and rapid progressive abdominal distension together with jaundice a week before admission. There was no fever, vomiting, bleeding from body orifices or bowel abnormality. Examination revealed jaundice, large tender smooth firm non pulsating hepatomegaly and mild splenomegaly with moderate ascites but no lower limb edema. Medical history was irrelevant. Laboratory workup revealed high AST, ALT and bilirubin $(220 \mathrm{mg} / \mathrm{dL}, 312 \mathrm{mg} / \mathrm{dL}$ and $7.1 \mathrm{mg} / \mathrm{Dl}$, respectively). Albumin, alkaline phosphatase and PC were normal $(3.9 \mathrm{~g} / \mathrm{dL}, 123 \mathrm{mg} / \mathrm{dL}$ and $83 \%$, respectively). Abdominal ultrasonography showed diffuse hepato-splenomegaly and ascites. Duplex scanning showed acute occlusive thrombosis of right, left and middle hepatic veins (Figure 1) and a chronic adherent thrombus occluding main portal vein with dilated collateral channels around "portal cavernoma" (Figure 2). IVC and hepatic vein confluence were patent. Upper GIT endoscopy revealed grade II esophageal varices. Diagnosis of acute Budd Chiari syndrome and portal vein thrombosis was confirmed. Thrombophilia screening showed hetereozygous factor VR2 (A4070G; H129R), heterozygous MTHFR C677T and MTHFR A1298C, a homozygous PAI-1 4G/4G and heterozygous ACE I/D. Patient was treated with LMWH followed by warfarin, patient

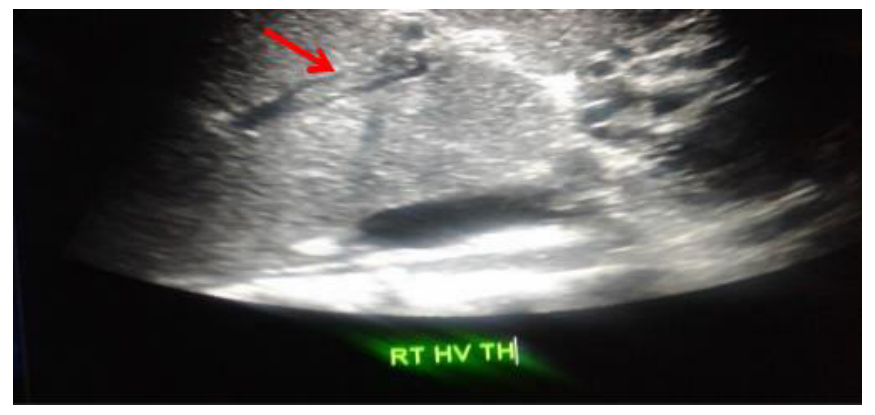

Figure 1: Hepatic vein thrombus. improved with resolution of jaundice, ascites and hepatomegaly with decline of transaminases and bilirubin after 3 weeks. INR was adjusted at 2.3 and follow up duplex scanning 6 weeks later revealed complete recanalization of hepatic veins but portal vein thrombus showed no change. Patient was discharged and advised to stop tramadol. Eight weeks later she returned to work and continued follow up in outpatient clinic.

\section{Discussion}

Thrombosis in portal and hepatic veins should be investigated as hereditary causes are common in splanchnic thrombosis and their presence raise the decision of life long anticoagulation. Homozygous PAI-1 4G/4G and MTHFR 677TT were found to have an important role in portal vein thrombosis and Budd Chiari Syndrome [1]. Other

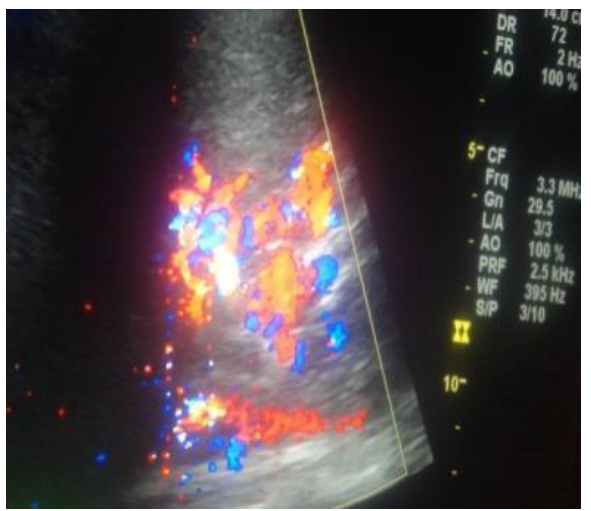

Figure 2: Portal vein cavernoma.

${ }^{*}$ Corresponding author: Afaf Hemeda, Department of Internal and Vascular Medicine, Kasr Al Eini Faculty of Medicine, Cairo University, Egypt, Tel: +20235676105; E-mail: afafhemeda25@gmail.com

Received July 31, 2017; Accepted September 12, 2017; Published September 22, 2017

Citation: Hemeda A (2017) Combined Hepatic and Portal Vein Thrombosis due to Uncommon Hereditary Factors for Thrombophilia in Young Adult. J Vasc Med Surg 5: 337. doi: 10.4172/2329-6925.1000337

Copyright: @ 2017 Hemeda A. This is an open-access article distributed under the terms of the Creative Commons Attribution License, which permits unrestricted use, distribution, and reproduction in any medium, provided the original author and source are credited. 
Citation: Hemeda A (2017) Combined Hepatic and Portal Vein Thrombosis due to Uncommon Hereditary Factors for Thrombophilia in Young Adult. J Vasc Med Surg 5: 337. doi: 10.4172/2329-6925.1000337

Page 2 of 2

study reported that multiple hereditary factors for thrombosis were found in 25\% of patients with Budd Chiari Syndrome [2] and others showed that at least one hereditary factor is present in Budd Chiari Syndrome and 2 factors or more in portal vein thrombosis [3]. Also, a significant association was found between ACE DD genotype and VTE and this was attributed to hypo-fibrinolysis by both increasing PAI-1 expression and decreasing t-PA production [4]. MTHFR C677 T heterozygous pattern was also found to be the third common inherited pro-thrombotic factor in portal vein thrombosis and Budd Chiari Syndrome in a study conducted on 57 and 48 patients, respectively, it comes after protein C and S [5]. Tramadol addiction as a cause of thrombosis is lacking and follow up of cases for longer periods is recommended [6].

\section{Conclusion}

This is a rare case of acute Budd Chiari syndrome with chronic thrombosis of portal vein in a young tramadol addict patient with multiple abnormality in thrombophilia screening including a heterozygous factor VR2 (A4070G;H129R), heterozygous MTHFR C677T \& MTHFR A1298C, heterozygous ACE I/D and a homozygous
PAI-1 4G/4G. Is tramadol addiction has a role in thrombosis or it is just a coincidence. Little data are present in literature as regards this issue.

\section{References}

1. Amico M, Sammarco P, Pasta L (2013) PAI-1 4G/4G and MTHFR 677TT had an important role in abdominal venous thrombosis. International Journal of Vascular Medicine.

2. Murad SD, Plessier M, Hernandez G, Fabris F, Eapen CE, et al. (2009) Etiology, management and outcome of Budd-Chiari syndrome. Annals of Internal Medicine 151: 167-175

3. Plessier A, Darwish MS, Hermandez GM, Consigny Y, Fabris F, et al. (2010) Acute PVT and BCS unrelated to cirrhosis: a prospective study. Hepatology 51: $210-218$

4. Fatini C, Gensini F, Sticchi E. (2003) Angiotensin converting enzyme homozygous pattern and venous thromboembolism. Eur J Clin Invest 33: 642-647.

5. Martreyee B, Govind M, Kannan M (2004) MTHFR C677 T heterozygous pattern was found to be the third common inherited pro-thrombotic factor in PVT and BCS. American Journal of Clinical Pathology 121: 844-847.

6. FDA Report (2017) Data collected from 79,416 tramadol addict, only 2 persons develop Budd Chiari Syndrome, this incidence denotes that tramadol in unlikely a cause of hepatic vein thrombosis. 